This PDF is a selection from a published volume from the National Bureau of Economic Research

Volume Title: Risk Topography: Systemic Risk and Macro Modeling

Volume Author/Editor: Markus Brunnermeier and Arvind Krishnamurthy, editors

Volume Publisher: University of Chicago Press

Volume ISBN: 0-226-07773-X (cloth); 978-0-226-07773-4 (cloth); 978-0-226-09264-5 (elSBN)

Volume URL: http://www.nber.org/books/brun11-1

Conference Date: April 28, 2011

Publication Date: August 2014

Chapter Title: Systemic Risk Exposures: A 10-by-10-by-10 Approach

Chapter Author(s): Darrell Duffie

Chapter URL: http://www.nber.org/chapters/c12512

Chapter pages in book: (p. 47 - 56) 


\title{
Systemic Risk Exposures \\ A 10-by-10-by-10 Approach
}

\author{
Darrell Duffie
}

Here, I present and discuss a "10-by-10-by-10" network-based approach to monitoring systemic financial risk. Under this approach, a regulator would analyze the exposures of a core group of systemically important financial firms to a list of stressful scenarios, say ten in number. For each scenario, about ten such designated firms would report their gains or losses. Each reporting firm would also provide the identities of the ten, say, counterparties with whom the gain or loss for that scenario is the greatest in magnitude relative to all counterparties. The gains or losses with each of those ten counterparties would also be reported, scenario by scenario.

Gains and losses would be measured in terms of market value and also in terms of cash flow, allowing regulators to assess risk magnitudes in terms of stresses to both economic values and also liquidity. Exposures would be

Darrell Duffie is the Dean Witter Distinguished Professor of Finance at the Graduate School of Business at Stanford University and a research associate of the National Bureau of Economic Research.

I am grateful for comments from Viral Acharya, Lewis Alexander, Niki Anderson, Peter Axilrod, Dick Berner, Markus Brunnermeier, Stacey Coleman, Rob Engle, Mike Fishman, Mark Flood, John Gidman, Tobi Guldimann, Anil Kashyap, John Khambu, Arvind Krishnamurthy, Joe Langsam, Clinton Lively, Stephen O'Connor, Mike Piwowar, Hélène Rey, and Chester Spatt, none of whom necessarily agree with any of the views expressed here. In June 2007, I suggested a preliminary version of this approach to the Financial Advisory Roundtable of the Federal Reserve Bank of New York. This chapter was prepared for a meeting on October 17, 2010, of the Systemic Risk Measurement Initiative of the National Bureau of Economic Research, of which I am a research associate. This approach has been presented to a number of regulators in Europe and the United States, whose comments have been extremely helpful. I am especially grateful to the editors of this volume, Markus Brunnermeier and Arvind Krishnamurthy. For nonacademic relationships that may present a potential conflict of interest, please see my web page at www.stanford.edu/ duffie/. For acknowledgments, sources of research support, and disclosure of the author's material financial relationships, if any, please see http://www.nber.org/chapters/c12512.ack. 
measured before and after collateralization. One of the scenarios would be the failure of a counterparty. The "top ten" counterparties for this scenario would therefore be those whose defaults cause the greatest losses to the reporting firm.

In eventual practice, the number of reporting firms, the number of stress scenarios, and the number of major counterparties could all exceed ten, but it is reasonable to start with a small reporting system until the approach is better understood and agreed upon internationally.

This systemic risk-monitoring system would be more effective if adopted by regulators in several major jurisdictions. Pooled reports that are based on coordinated choices of stress scenarios would reveal systemic risk more comprehensively.

With such a monitoring system in place, a regulator charged with supervision of the stability of the financial system would be in a position to quickly answer a range of questions concerning concentrations of stress on the central nodes and links of the system. Examples of the questions that could arise include the following:

1. Is it true that some large hedge funds have taken significant foreignexchange positions with systemically important banks? Who are these hedge funds? Do any of them also pose potentially large counterparty default exposures to any of these banks? How large are the associated market-value and cash-flow impacts?

2. If treasury yields were to rise dramatically, how much would systemically important financial institutions gain or lose in total, from each other and from others?

3. How prominent are central clearing counterparties (CCPs) among the top counterparties to systemically important firms?

4. What sorts of major financial firms have short positions with respect to real estate markets, and with whom do they hold their largest positions in this asset class?

5. Do the exposure results obtained from the reporting firms allow us to identify any previously undetected systemically important firms?

Although 10-by-10-by-10 reports would be collected from a small number of designated firms, the results would likely shed light on risk flows between these firms and potentially many other firms. Because of this, a regulator may be able to identify nonreporting firms that are candidates to be designated as systemically important, and perhaps also be added to the list of reporting firms. This process of augmenting the reported network can be iterated. An analysis of 10-by-10-by-10 data could also trigger follow-up supervisory conversations between regulators and individual firms, or groups of firms. For example, a regulator might wish to alert a group of banks that they have significant exposures in the same asset class and in the same direction with a concentrated common set of counterparties. 
It is to be emphasized that this approach to systemic risk monitoring is much broader than a counterparty default exposure measurement system, although counterparty default exposures are included in it. For a given scenario, large gains shed as much light on risk flows through the financial system as do large losses. Moreover, even if reported gains and losses do not threaten the viability of reporting firms or their immediate counterparties, they may be important clues to the magnitudes of risk flows in given asset classes, and may allow regulators to consider the potential for contagion through fire sales.

Under this monitoring scheme, once revised and implemented, the reporting entities would provide the stipulated measures periodically, say quarterly, to designated regulators. Regulators from various jurisdictions would pool and then analyze the data. The overall objective would be to monitor the exposure of the financial system to systemically important stresses. The joint exposure of the system to the performance of particular asset classes, macroeconomic events, and entities (or chains of entities) could, as a result, be clarified. Summary information could be publicly disclosed, for example, in the form of histograms or population statistics, making a reasonable trade-off of the costs and benefits of releasing firm-specific or detailed data. For example, the Financial Services Authority of the United Kingdom has provided semiannual reports of the default exposures of UK banks to hedge fund counterparties. Public knowledge of summary information regarding stresses across the financial system of various types may contribute to an endogenous lowering of critical stresses through repricing and portfolio adjustments.

Regulators may choose to be cautious, however, about creating additional uncertainty, or potentially even triggering runs, through public reporting of detailed firm-specific contemporaneous stress information. ${ }^{1}$ Rather, their objective may be to alert themselves and the public to potential sources of financial instability before they reach dangerous levels.

Full and immediate public disclosure of firm-specific stress reports could also dampen the incentives of reporting firms to act as liquidity providers, temporarily warehousing risk, as modeled by Grossman and Miller (1988) and Brunnermeier and Pedersen (2009). Intermediaries would expect more severe price impacts when unloading large positions if the sizes of their positions are known publicly. Bid-offer spreads would widen, and market liquidity could suffer as a result. For similar reasons, in the face of instant public disclosure of their positions, the incentives to gather fundamental information would be reduced, worsening the price-discovery function of financial markets.

1. The security of the data is clearly a concern, and this should figure carefully into the design of the reporting system. It should be possible, if desired, to use encryption methods to ensure that even some regulators are unable to fully disaggregate the data. 
Separate analysis would likely suggest criteria for the selection of important stress scenarios, as well as precise instructions for stress measurement. It is natural to specify extreme-but-plausible scenarios for changes in market prices, or performance of nonpriced instruments, that could occur within, say, one quarter. The relevant shocks are those likely to have occurred conditional on a major financial crisis. Illustrative examples of these scenarios could include the following:

1. The default of a major entity

2. A 4 percent simultaneous change in all credit yield spreads

3. A 4 percent shift of the US-dollar yield curve

4. A 25 percent change in the value of the dollar relative to a basket of major currencies

5. A 25 percent change in the value of the euro relative to a basket of major currencies

6. A 25 percent change in a major real estate index

7. A 50 percent simultaneous change in the prices of all energy-related commodities

\section{A 50 percent change in a global equities index}

The asset classes covered by these scenarios are broad, keeping the reporting system relatively simple and robust. While individual financial firms may be heavily exposed to long-short strategies within an asset class, major financial crises are more likely to be connected with severe price movements across a large asset class.

Much of the required reporting methodology is within the scope of current state-of-the-art risk-management systems used by major financial institutions. ${ }^{2}$ For example, it is somewhat routine for major banks to monitor their largest credit exposures, incorporating for each major counterparty all significant contractual positions, covering loans, bonds, equities, over-

2. For example, J.P. Morgan's 10Q disclosure for June 2010 states: "The Firm conducts economic-value stress tests using multiple scenarios that assume credit spreads widen significantly, equity prices decline and significant changes in interest rates across the major currencies. Other scenarios focus on the risks predominant in individual business segments and include scenarios that focus on the potential for adverse movements in complex portfolios. Scenarios were updated more frequently in 2009 and, in some cases, redefined to reflect the significant market volatility which began in late 2008. Along with VaR, stress testing is important in measuring and controlling risk. Stress testing enhances the understanding of the Firm's risk profile and loss potential, and stress losses are monitored against limits. Stress testing is also utilized in one-off approvals and cross-business risk measurement, as well as an input to economic capital allocation. Stress-test results, trends and explanations based on current market risk positions are reported to the Firm's senior management and to the lines of business to help them better measure and manage risks and to understand event risk-sensitive positions." SEC Financial Reporting Release 48 and International Financial Reporting Standard 7 mandate disclosure of value at risk or sensitivities to various market stresses. The IFRS7 requires sensitivities to interest rates, currencies, and "other price risk" (for example, that from equities and commodities), including the impact on profits and on firm equity for "reasonably possible" changes in the relevant variable (Section 40). The New York Fed, through its supervisory monitoring program, collects information from reporting banks on the sensitivities to key risk factors of the market values of their trading and held-to-maturity assets that are marked to market. The 
the-counter derivatives, and loan guarantees. Likewise, the gain or loss in market value associated with a return scenario of the sort shown in the abovementioned list is often captured within existing risk-management systems by replacing the current market prices used for monitoring the values of positions with the stipulated artificial prices, and then recalculating position values. ${ }^{3}$ The total change in value is the reported gain or loss. All positions that are contractually linked to the indicated price scenario must be identified, scenario by scenario. At least in terms of methodology, this is a conventional approach for large sophisticated banks and large hedge funds. Notably, this approach is "model-free." That is, from the viewpoint of reporting firms, the stress scenarios are precisely defined deterministic scenarios provided by the regulator. The reporting firms would not use model-based probabilistic methods, such as those applied for value-at-risk measurement.

In order to calculate the cash-flow impacts of a scenario, substantial contractual detail would need to be captured by a risk-management system. Cash-flow impacts include those associated with collateral exchanges, option exercises, termination settlement of OTC derivatives, debt payments (or lack thereof), and so on. Some of the likely reporting firms may not have the information technology needed to collect and aggregate the cash-flow impacts of shocks to major asset classes, particularly with respect to specific counterparties. This capability, going beyond that required for measuring Basel III liquidity coverage ratios, would need to be added to their riskreporting systems.

Brunnermeier, Gorton, and Krishnamurthy (2012) have proposed a new measure of balance-sheet liquidity that would be complimentary to the cash-flow stress measures proposed here. Notably, their liquidity measure addresses the ability of a reporting firm to withstand a liquidity shock.

For asset classes that are not marked to market, such as the nontraded loan books of major banks, scenarios can be converted by regulators into stipulated default losses or other performance losses, as has been done in some cases for the recent system-wide bank-capital stress tests of the United States and the Eurozone.

A macroeconomic scenario, such as a reduction in the growth rate of gross domestic product, can be converted by regulators into stipulated return shocks for positions that are marked to market, or into stipulated rates of loss for nontraded loan books. One is interested in the expected gain or loss in value (or cash-flow impact) of each asset class, conditional on the

Federal Reserve System currently collects additional information on the sensitivities of the portfolios of banks to specified risk factors. The comments of Fed governor Daniel Tarullo, of February 2010, suggest ongoing efforts in this direction, and the need to further study systemic linkages.

3. An alternative is a "delta-based" approach, by which the sensitivity of a position value to a unit shift in the underlying price is multiplied by the stipulated price change. With extreme scenarios, the delta-based approach would be inaccurate for nonlinear positions, such as options. 
scenario. These return or performance shocks would be estimated by the regulator and provided to all reporting firms as inputs to their reporting methodology. In this way, standardization is promoted. Standardization is particularly valuable in a network setting in which one hopes to follow the transmission of financial shocks from node to node through the network. Standardization also reduces noise and moral hazard that would otherwise arise in the interpretation by reporting firms of broadly defined macroeconomic stresses.

Likewise, in designing a stress scenario, a regulator interested in the all-in impact of a shock to a particular asset class could stipulate the given return shock to that asset class, as well as the expected returns to all other major asset classes conditional on the return shock to the target asset class. ${ }^{4}$ As such, each scenario is specified by regulators and passed to reporting firms as a list of deterministic returns or performance shocks to all asset classes.

Some care would be needed to ensure that all, or at least the vast majority, of a reporting firm's positions are mapped to associated exposures by asset classes. This is already standard practice for the risk-management systems in use by many large financial firms, but the list of asset classes and the methodologies that are currently used for these instrument-to-asset-class mappings differ across firms.

One of the stipulated scenarios, the default of a single entity, entails a calculation of the total loss associated with the failure of an issuer, borrower, or OTC counterparty, combining all contractual exposures, including debt, equity, securities lending, and derivatives. The regulator could specify a fractional loss of value given default, or require reports based on zero recoveries. The associated ten counterparties for this stress would be those whose defaults would lead to the greatest losses to the reporting firm. These entities could often include sovereigns, quasi sovereigns, and financial utilities such as central clearing parties.

The UK Financial Services Authority (FSA) already conducts a regular survey of the exposures to hedge funds (only) of UK banks. For example, in July 2010, the FSA reported that the maximum potential credit exposure (which includes the effect of ten-day, 99 percent value at risk) of any one bank to any one hedge fund was approximately $\$ 600$ million.

A significant amount of work may be needed in order to refine the definitions of the exposure measures, including distinctions between gross and net losses. For example, a given scenario loss could be measured as follows:

1. On a mark-to-market basis, assuming no collateral and allowing for netting only within legally enforceable master netting agreements. In this case, the measured gain or loss would effectively assume that any potentially netting offsets of gains or losses with a single counterparty cannot be real- 
ized except where clearly required by master netting agreements, and would be measured before offsetting reductions allowed by collateralization.

2. On a net mark-to-market basis, after the use of collateral and legally enforceable netting.

3. On a cash-flow basis, within a prescribed time period such as thirty days, the duration standard for the Basel III liquidity coverage ratio requirement.

Notwithstanding the ability of a reporting entity to offset losses by applying collateral, gross-of-collateral exposure measures may assist regulators in understanding the magnitudes of risks for a given asset class flowing across specific links in the financial system, and also permit them to consider the potential impact of asset fire sales, including sales of collateral. The objective is to capture systemic linkages, whether or not by virtue of collateral, that expose the reporting financial institution to significant losses. Likewise, the largest counterparties for a given scenario are selected on the basis of the absolute magnitude of the gain or loss, and not on the basis of the loss to the reporting institution.

\subsection{Some Shortcomings}

A shortcoming of the 10-by-10-by-10 approach is that the total sensitivity of a financial entity to some relatively broadly defined risk factor may be moderate, while at the same time the entity has dangerously large long and short exposures within the broadly specified risk class. For example, the 2006 failure of the hedge fund Amaranth Advisors LLC was caused by approximately $\$ 6.5$ billion in losses on roughly equally sized long and short positions in natural gas futures contracts for two different delivery months, March and April 2007, respectively. Similarly, the significant losses of certain "quant equity" hedge funds in August 2007 stemmed from long and short equity positions that left these funds relatively unexposed to a shift in the overall level of major stock indices. The general concern that the defined risk factors may be too broad to capture some important narrowly concentrated exposures is mitigated by the likelihood that firm-threatening exposures to relative movements within a well chosen broad risk factor are likely to be held by a relatively small set of firms. In any case, nothing rules out the selection of long-short or cross-market stresses if these are believed to be among the most important potential shocks to the financial system.

Another shortcoming of the 10-by-10-by-10 approach is that it would miss widely dispersed potential sources of systemic risk that do not flow through major financial institutions. For example, the US savings and loan crisis of the 1980s did not present large, directly measurable stresses to systemically important financial institutions. The 10-by-10-by-10 approach captures only those sources of stress that pass through the center of the financial system. Regulators could perhaps augment with additional network-based stress analysis that reaches more broadly into the financial system. 
The magnitudes of losses caused by a specific stress do not on their own determine whether a firm has the necessary capital and liquidity to withstand the stress without failure. The data provided through 10-by-10-by-10 reports may be useful in judging the ability of firms to withstand important shocks, but for that purpose would need to be accompanied by additional firm-specific capital and liquidity measures. In that sense, 10-by-10-by-10 reports could provide useful data for the supervisory analysis of systematically important firms.

Essentially any stress measurement system is subject to a financial riskmanagement analogue of the Heisenberg uncertainty principle, by which increasing the precision of one's measurement of one aspect of a system merely increases uncertainty regarding other dimensions of the system. This endogeneity is similar to that of the well-known "Lucas critique." The shareholders and some of the employees of a financial institution often have an incentive to take more risk than is socially optimal because they do not internalize the costs of systemic risk. When a regulator focuses on a particular risk measure, a reporting financial institution may adjust its risk-taking behavior so as to lower this risk measure while raising its risk elsewhere.

For example, regulators commonly focus on "value at risk," the loss on a given portfolio that is exceeded with a small defined probability, say 5 percent. A reporting financial institution may, as a result, choose to increase its exposure to losses that occur with a smaller probability than 5 percent. Similarly, if a regulator measures the exposure of a bank to a 25 percent change in the value of an asset, the bank could buy and sell options on the asset so as to lower this particular exposure, while raising its exposure to a 30 percent change in the value of the asset. In the face of concerns about this form of window dressing, a regulator could request the impacts to a graduated range of shock magnitudes, from moderate to large. In general, by limiting the stress measures to a small number of extremely broad asset classes, the Heisenberg uncertainty principle is significantly mitigated, but is not eliminated.

Eventually, regulators may have sufficient instrument-level data to directly conduct risk analyses without reliance on reporting by the firms they are monitoring. This would dramatically increase the range of tests and studies that could be conducted, and lower concerns over standardization of the implementation across reporting firms, as well as window-dressing behavior. On the other hand, the cost and time delays associated with comprehensive and accessible instrument-level regulatory databases currently seem large, to say the least. In any case, the ability of each reporting firm to administer stress reports within its own risk-management system is of some independent risk-management value.

The greater the standardization of risk measures, the greater is the danger of "groupthink"; that is, an unhelpful common focus or agreement on what matters, in the presence of unconsidered relevant alternatives. Groupthink 
that is caused by a common industry-wide risk-measurement approach could lower the chance that important alternative sources of systemic risk would be identified by creative individual analysis, or would be brought forward for treatment once identified.

Further, standardization of risk measures may encourage common approaches to hedging or speculation that could destabilize markets if a significant number of important financial institutions rush toward a common exit from dangerous positions that are identified by a dramatic increase in a specific standardized risk measure.

\subsection{Could This Have Made a Difference in the Last Financial Crisis?}

The financial crisis of 2007 to 2009 was triggered by significant losses in assets linked to subprime residential mortgages. As the crisis developed, the systemic risks became increasingly related to broader real estate-related asset classes, to broader debt-market pricing, and to counterparty exposures; for example, through derivatives and repo markets. Is it plausible that, without a hindsight advantage, a " $n$-by- $n$-by- $n$ " monitoring scheme could have made a significant difference in the ability of regulators to visualize the buildup of systemic risk that occurred prior to the onset of the crisis?

Residential mortgages form one of the largest underlying asset classes to which systemic investors are exposed, and a common epicenter for financial crises. It is more than plausible that one or more of the stress scenarios specified by regulators would have picked up a substantial buildup of network exposure to mortgage-related assets well in advance of the crisis. After all, we now know that several major likely reporting financial institutions, including UBS, Citibank, Bank of America, and Merrill Lynch, each had tens of billions of dollars of losses related to the subprime mortgages alone. The underlying position sizes took many quarters to build.

With the benefit of " $n$-cubed" reports, regulators would have observed the growing exposures of the reporting institutions themselves. Perhaps these exposures were already available to regulators through other forms of bank supervisory reporting. The $n$-cubed reports would also have revealed increasing and changing network flows of risk related to mortgages. In particular, even if it had not been an $n$-cubed reporting firm, AIG would likely have been identified as a significant source of counterparty exposure to several systemically important reporting financial institutions. We now know this because, in the breech, regulators were forced to rescue AIG because of the life-threatening exposures to AIG of a number of major global banks, through the losses they would have otherwise incurred through their contractual positions with AIG on mortgage-related contracts with AIG. Again, these exposures would have taken a number of quarters to build toward the extremely large sizes they ultimately reached, and so the buildup would likely have been identified in advance. If, as a result, AIG had been 
asked "join the grid" and begin reporting to an " $(n+1)$-cubed" monitoring system, the resulting network risk map would have presumably identified AIG's own aggregate exposure to the underlying residential mortgage asset class. (A side benefit is that AIG's directors would have had a better chance to have become informed of their firm's growing exposure to the asset class.) Further, additional nonreporting firms that were exposed to AIG would likely have been identified, including perhaps some foreign banks, had they not already been reporting to a global version of the $n$-cubed system.

One should also consider whether, even with the benefit of an $n$-cubed monitoring system, regulators would have taken appropriate note of the changing network risk flows related to mortgage-related assets. Because the mortgage-related asset class is always enormous, would the increasingly dangerous exposures to AIG have set off concerns and been elevated for further action by macro- or microprudential supervisors? Perhaps.

If the monitoring system had been too complex or had it provided an overwhelming amount of undigested data, the growing dangers could have remained "in plain sight" but undetected. If the system had been too sparse, some important points of fragility could have been be missed.

A lesson of the crisis is the importance of access to carefully designed network-based risk monitoring systems, and of investigating the causes of changes in the character of risk flows as they occur.

\section{References}

Basel Committee on Banking Supervision. 2004. "Principles for the Management and Supervision of Interest Rate Risk." Basel: Bank for International Settlements. July. http://www.bis.org/publ/bcbs108.pdf?noframes=1.

Brunnermeier, Markus, Gary Gorton, and Arvind Krishnamurthy. 2012. "Risk Topography." In NBER Macroeconomics Annual 2011, edited by Daron Acemoglu and Michael Woodford, 149-83. Chicago: University of Chicago Press.

Brunnermeier, Markus, and Lasse Pedersen. 2009. "Market Liquidity and Funding Liquidity." Review of Financial Studies 22:2201-38.

Financial Services Authority. 2010. "Assessing Possible Sources of Systemic Risk from Hedge Funds: A Report on the Findings of the Hedge Fund as Counterparty Survey and Hedge Fund Survey." London: United Kingdom Financial Services Authority. July. www.fsa.gov.uk/pubs/other/hedge_funds.pdf.

Grossman, S. J., and M. H. Miller. 1988. "Liquidity and Market Structure.” Journal of Finance 43:617-33.

Tarullo, Daniel. 2010. "Equipping Financial Regulators with the Tools Necessary to Monitor Systemic Risk." Testimony before the Senate Subcommittee on Security and International Trade and Finance, Committee on Banking, Housing, and Urban Affairs, Washington, DC, February 12. http://www.federalreserve.gov /newsevents/testimony/tarullo20100212a.htm. 